\title{
O PROEJA E A REFORMA DO ENSINO MÉDIO (LEI № 13.415/2017)
}

\author{
A. L. S. HENRIQUE \\ Instituto Federal de Educação, Ciência e Tecnologia do Rio Grande do Norte \\ ana.henrique@ifrn.edu.br
}

Submetido 27/02/2018 - Aceito 26/03/2018

DOI: $10.15628 /$ holos.2018.6903

\section{RESUMO}

O presente artigo pretende discutir a reforma do Ensino Médio e suas consequências para o Proeja. Partimos do pressuposto de que essa reforma afeta diretamente o Ensino Médio Integrado à Educação Profissional, pois acaba com a ideia de integração e vai de encontro ao direito de educação básica comum e igual para todos. Além disso, nega aos jovens e adultos o que, historicamente, já lhes foi negado: o direito a uma educação que thes permita inserção social e no mundo do trabalho. Partimos de revisão bibliográfica sobre o EJA (HADDAD e DI PIERRO, 2000; PAIVA, 2005) e o Proeja (MOURA E HENRIQUE, 2012; MOURA, 2016), aliada à análise documental (BRASIL, 1996; BRASIL, 2007; BRASIL, 2017a; BRASIL 2017b). A análise mostra que, embora não se refira à modalidade EJA em seu teor, a reforma do Ensino médio promulgada pelo Governo Federal é mais um passo para a descontinuidade ou atrofia do Proeja.

PALAVRAS-CHAVE: Proeja, reforma do Ensino Médio, educação de jovens e adultos.

\section{THE PROEJA AND THE HIGH SCHOOL REFORM (LAW No. 13.415 / 2017)}

\begin{abstract}
The present article intends to discuss the reform of High School and its consequences for Proeja. We start from the assumption that this reform directly affects the Integrated Higher Education to Vocational Education, because it ends with the idea of integration and goes against the right of basic education common and equal for all. Moreover, it denies to young people and adults what has historically been denied them: the right to an education that allows them to enter socially and in the
\end{abstract} the EJA (HADDAD and DI PIERRO, 2000) and Proeja (MOURA and HENRIQUE, 2012; MOURA, 2016), allied to documentary analysis (BRASIL, 1996, BRAZIL, 2017a ; The analysis shows that, although it does not refer to the EJA modality in its content, the reform of the Secondary School promulgated by the Federal Government is another step towards the discontinuity or atrophy of Proeja. 


\title{
1 CIRCUNSCREVENDO O NOSSO OBJETO
}

\begin{abstract}
Nesses cenários em mudança, a educação de jovens e adultos vem lutando - e resistindo - pelo espaço de existir/não existir; ser/não ser, em busca da constituição de um lugar de direito para se fazer a humanidade de muitos homens e mulheres, [...] (PAIVA, 2005, p.148)
\end{abstract}

O pressuposto de que parto para análise da reforma do Ensino Médio com a promulgação da Lei № 13.415/2017 e sua relação com o Proeja é a de que essa reforma afeta diretamente o Ensino Médio Integrado à Educação Profissional, pois acaba com a ideia de integração e vai de encontro ao direito de educação básica comum e igual para todos. Além disso, nega aos jovens e adultos o que, historicamente, já lhes foi negado: o direito a uma educação socialmente referenciada, uma formação integral por meio de cursos que integrem trabalho, ciência, tecnologia e cultura como eixos estruturantes do currículo e que lhes permita inserção social e no mundo do trabalho. Partimos de autores que discutem a EJA e o Proeja (HADDAD e DI PIERRO, 2000; PAIVA, 2005; HENRIQUE e MOURA, 2012; MOURA, 2016) e de análise documental (BRASIL, 1996; BRASIL, 2007; BRASIL, 2017a; BRASIL 2017b), para analisar a relação entre a Lei № 13.415/2017 e o Proeja.

Para a consecução desse objetivo, neste artigo, inicialmente situaremos a discussão de nosso objeto na histórica descontinuidade das políticas para a modalidade de educação de jovens e adultos no país, para, em seguida, apresentar o Proeja como uma das ações para a EJA, que já vem passando por uma redução de incentivos governamentais. Tentaremos mostrar que a reforma do EM tal como está proposta na legislação é um obstáculo à materialização do Ensino Médio Integrado (EMI) e, consequentemente, do Proeja.

\section{A EDUCAÇÃO DE JOVENS E ADULTOS NO BRASIL: A REGULARIDADE DA DESCONTINUIDADE}

A epígrafe que abre este trabalho mostra a postura, não só de Paiva (2005) mas de todos os pesquisadores que têm como objeto de estudo a EJA e as políticas de governo para essa modalidade. Haddad e Di Pierro (2000), em um texto que oferece uma rápida visão panorâmica do tema ao longo dos cinco séculos da história com especial atenção à segunda metade do século XX, evidenciam que a Educação de Jovens e Adultos (EJA), no Brasil, é marcada por descontinuidades e por políticas pontuais e desarticuladas. Historicamente, as ações nessa modalidade são desenvolvidas por meio de programas, de campanhas e de projetos fragmentados, resultando em ações focais que não têm garantido o direito dos jovens e adultos à educação na perspectiva de sua universalização.

Lembram Haddad e Di Pierro (2000) que, já na primeira constituição brasileira de 1824, estava explícita a garantia de instrução primária e gratuita para todos os cidadãos. À época, essa intenção (que se manifestou em outras constituições brasileiras posteriores), entretanto, não teve materialização em políticas públicas, ou seja, "O direito que nasceu com a norma constitucional de 1824, estendendo a garantia de uma escolarização básica para todos, não passou da intenção legal." (HADDAD; DI PIERRO, 2000, p.109). A Constituição de 1891 passou a 
responsabilidade do ensino básico para as províncias e municípios, ficando sob responsabilidade da União o ensino secundário e superior, o que fragilizou ainda mais o incipiente ensino básico, já que

Mais uma vez garantiu-se a formação das elites em detrimento de uma educação para as amplas camadas sociais marginalizadas, quando novamente as decisões relativas à oferta de ensino elementar ficaram dependentes da fragilidade financeira das Províncias e dos interesses das oligarquias regionais que as controlavam politicamente. (HADDAD; DI PIERRO, 2000, p.109).

Nesse período, houve, ainda segundo os autores, uma grande quantidade de reformas educacionais que não se preocuparam com o estado precário do ensino básico e não produziram efeitos, uma vez que não havia dotação orçamentária que pudesse garantir uma ação eficaz. Como resultado, 30 anos após o estabelecimento da República no país, o censo de 1920 indicou que $72 \%$ da população acima de cinco anos permanecia analfabeta.

No Período de Vargas, com a Constituição de 1934, o ensino primário integral gratuito e de frequência obrigatória foi extensivo aos jovens e adultos. Essa ação coincidia também com o princípio da industrialização, com a aceleração da urbanização no Brasil e com demandas internacionais como a criação da UNESCO e sua denúncia ao mundo relativa às profundas desigualdades entre os países, em que alertava para o papel que deveria desempenhar a educação, em especial a educação de adultos, no processo de desenvolvimento das nações consideradas atrasadas. Apoiados na discussão dos autores, podemos concluir que essa preocupação com a EJA estava atrelada às necessidades de mão de obra para atender às demandas do mercado de trabalho. Em outras palavras, veio com o "fim de prover qualificações mínimas à força de trabalho para o bom desempenho aos projetos nacionais de desenvolvimento propostos pelo governo federal." (HADDAD; DI PIERRO, 2000, p.111).

Ainda que os esforços do governo federal não estejam atrelados ao direito à educação em si mesmo, os autores supracitados lembram que "Os esforços empreendidos durante as décadas de 1940 e 1950 fizeram cair os índices de analfabetismo das pessoas acima de cinco anos de idade para 46,7\% no ano de 1960." (HADDAD; DI PIERRO, 2000, p.111).

O período que antecedeu o golpe militar foi de intensa movimentação social e de redirecionamento das ações voltadas para o público jovem e adulto com o reconhecimento das especificidades desse público, e, portanto, com o reconhecimento da necessidade de modelo pedagógico distinto e material didático específico. Entre esses programas, que estavam funcionando no âmbito do Estado ou sob seu patrocínio, estão o Movimento de Educação de Base (MEB), da Conferência Nacional dos Bispos do Brasil (CNBB), estabelecido em 1961; o Movimento de Cultura Popular do Recife (MCP), a partir de 1961; os Centros Populares de Cultura, órgãos culturais da União Nacional dos Estudantes (UNE); a Campanha De Pé no Chão Também se Aprende a Ler, da Secretaria Municipal de Educação de Natal; e, finalmente, em 
1964, o Programa Nacional de Alfabetização, do Ministério da Educação e Cultura, que contou com a presença do professor Paulo Freire. Nesse período,

\begin{abstract}
À medida que a tradicional relevância do exercício do direito de todo cidadão de ter acesso aos conhecimentos universais uniu-se à ação conscientizadora e organizativa de grupos e atores sociais, a educação de adultos passou a ser reconhecida também como um poderoso instrumento de ação política. Finalmente, foi-lhe atribuída uma forte missão de resgate e valorização do saber popular, tornando a educação de adultos o motor de um movimento amplo de valorização da cultura popular. (HADDAD; DI PIERRO, 2000, p.113).
\end{abstract}

O golpe civil-militar de 64 veio interromper esse movimento em prol da educação popular com a prisão dos principais dirigentes, a apreensão de material didático e a censura de seus ideais. Transcrevo, pela acuidade, as palavras de Haddad e Di Pierro (2000) relativas à ação do governo contra os movimentos de educação popular.

\begin{abstract}
A repressão foi a resposta do Estado autoritário à atuação daqueles programas de educação de adultos cujas ações de natureza política contrariavam os interesses impostos pelo golpe militar. A ruptura política ocorrida com o movimento de 64 tentou acabar com as práticas educativas que auxiliavam na explicitação dos interesses populares. O Estado exercia sua função de coerção, com fins de garantir a "normalização" das relações. (HADDAD; DI PIERRO, 2000, p.113, grifo dos autores)
\end{abstract}

Entretanto, o Estado nacional não podia prescindir da escolarização de jovens e adultos principalmente, porque a manutenção dos baixos níveis de escolaridade da população era incompatível com a proposta de país desenvolvido que os militares se propunham a construir. Nesse sentido, ao lado da existência de movimentos civis de resistência, o Governo apoiou e/ou criou ações como a Cruzada de Ação Básica Cristã ( $A B C)$, que contou com o apoio de evangélicos norte-americanos que, de maneira assistencialista servia aos interesses do regime militar; o Movimento Brasileiro de Alfabetização (MOBRAL); e, posteriormente, a implantação do Ensino Supletivo, em 1971, quando da promulgação da Lei Federal 5.692/1971, seguidos da Parecer do Conselho Federal de Educação № 699/1972, de autoria de Valnir Chagas, e o documento Política para o Ensino Supletivo também de 1972, produzido por um grupo de trabalho, com a relatoria do mesmo Valnir Chagas.

Sobre o MOBRAL, segundo Haddad e Di Pierro (2000), Paiva (1982) lembra que, em 1969, ele começa a se distanciar da proposta inicial, mais voltada aos aspectos pedagógicos, pressionado pelo endurecimento do regime militar, acrescentando que

${ }^{1}$ PAIVA, Vanilda Pereira. (1981-1982). MOBRAL: um desacerto autoritário I, II e III. Rio de Janeiro: Síntese, Ibrades, n. 23-24. 
[...] buscava-se ampliar junto às camadas populares as bases sociais de legitimidade do regime, no momento em que esta se estreitava junto às classes médias em face do Al-5, não devendo ser descartada a hipótese de que tal movimento tenha sido pensado também como instrumento de obtenção de informações sobre o que se passava nos municípios do interior do país e na periferia das cidades e de controle sobre a população. Ou seja, como instrumento de segurança interna. (PAIVA, 1982, p. 99).

Não é cerne desta discussão o aprofundamento sobre esse movimento de alfabetização, que contou com apoio irrestrito do governo militar do período, principalmente, do Presidente Médici. Importa aqui registrar a pouca preocupação pedagógica na fase mais profícua de sua existência e seu uso como instrumento de contenção social e de segurança nacional. Na época do milagre econômico brasileiro, a educação de adultos situava-se "na linha de frente das operações", por ser "poderosa arma capaz de acelerar o desenvolvimento, o progresso social e a expansão ocupacional como elemento prioritário dos projetos para o desenvolvimento" ${ }^{2}$.

Com a assunção do governo civil, o Mobral, cuja imagem pública ficara profundamente identificada com a ideologia e as práticas do regime militar, foi extinto dando lugar, ainda em 1985, à Fundação Nacional para Educação de Jovens e Adultos, a Fundação Educar. Transformada em órgão de fomento e apoio técnico e subordinada à Secretaria de Ensino de 1으 e 2 o Graus do MEC, a Educar

assumiu a responsabilidade de articular, em conjunto, o subsistema de ensino supletivo, a política nacional de educação de jovens e adultos, cabendo-lhe fomentar o atendimento nas séries iniciais do ensino de 10 grau, promover a formação e o aperfeiçoamento dos educadores, produzir material didático, supervisionar e avaliar as atividades. (HADDAD; DI PIERRO, 2000, p.120).

Nesse período da vida política brasileira, houve o recrudescimento e a (re)organização dos movimentos sociais urbanos e rurais, que permitiram tanto a inovação pedagógica como o retorno ao ideário da educação popular, que ganharam visibilidade. Conforme estudo de Haddad e Di Pierro (2000), esse processo de revitalização do pensamento e das práticas de educação de jovens e adultos refletiu-se na Assembleia Nacional Constituinte e foi materializado no Artigo 208 da Constituição de 1988, em que está expresso que o dever do Estado com a educação será efetivado, entre outras obrigações, mediante a garantia de ensino fundamental, obrigatório e gratuito, inclusive para os que a ele não tiveram acesso na idade própria.

Em 1990, no início de seu governo, Fernando Collor de Mello extinguiu a Fundação Educar. Com isso, os órgãos públicos, as entidades civis e outras instituições conveniadas, a partir daquele momento, tiveram que arcar sozinhas com a responsabilidade pelas atividades educativas anteriormente mantidas por convênios com a Fundação. Em seu lugar, foi criado o

\footnotetext{
2 Trechos do documento Adult Education in Brazil, destinado à III Conferência Internacional de Educação de Adultos, convocada pela UNESCO para Tóquio, 1972.
} 
Programa Nacional de Alfabetização e Cidadania (PNAC), que, com o impeachment do presidente foi descontinuado no Governo Itamar Franco. Na era FHC, em1996, foi aprovada a Lei de Diretrizes e Bases da Educação Nacional, № 9.394/1996, pouco inovadora em relação à educação de jovens e adultos. Em dois artigos, reafirma, de um lado o direito dos jovens e adultos trabalhadores ao ensino básico adequado às suas condições, e, de outro, o dever do poder público em oferecê-lo gratuitamente na forma de cursos e exames supletivos. Como novidades, trouxe a diminuição das idades mínimas para que os jovens se submetam aos exames supletivos, fixadas em 15 anos para o ensino fundamental e 18 anos para o ensino médio e a integração orgânica da educação de jovens e adultos ao ensino básico comum.

Em 1997, o presidente Fernando Henrique Cardoso criou o Programa Alfabetização Solidária (PAS), que recebeu duras críticas dos especialistas pelo conceito estreito de alfabetização com o qual trabalhava e pelo baixo número de jovens que conseguiu alfabetizar. Em 1998, é instituído o Programa Nacional de Educação na Reforma Agrária (PRONERA), cuja preocupação inicial era alfabetização de trabalhadores rurais assentados que se encontravam na condição de analfabetismo absoluto. Nascido de movimentos da sociedade civil, hoje, por meio do Pronera, trabalhadores rurais acampados e cadastrados pelo Incra têm acesso a cursos de educação básica (alfabetização, ensinos fundamental e médio), técnicos profissionalizantes de nível médio, cursos superiores e de pós-graduação (especialização e mestrado) ${ }^{3}$.

No governo de Luiz Inácio Lula da Silva, cria-se, em 2003, o Programa Brasil Alfabetizado (PBA), com o objetivo de universalizar a Alfabetização de jovens, adultos e idosos. Outra ação do Governo Lula para EJA foi o Programa de Integração da Educação Profissional à Educação Básica na Modalidade Educação de Jovens e Adultos (PROEJA), criado, em 2005, pelo Decreto № 5.478 e alterado, depois, pelo Decreto № 5.840/2006 ${ }^{4}$. Por tratar-se do objeto de nossa análise, discutiremos essa ação governamental, de forma mais aprofundada no item subsequente.

\section{O PROEJA: DO ENSINO MÉDIO INTEGRADO À FRAGMENTAÇÃO PROPOSTA PELA LEI № $13.415 / 2017$}

O Programa nasceu com uma dupla finalidade, enfrentar as descontinuidades e o voluntarismo que marcaram a EJA no Brasil; e integrar a Educação Básica (EB) a uma formação profissional que contribuísse para a integração socioeconômica de qualidade dos jovens e adultos na sociedade. Nessa dupla finalidade, está radicado o desafio fundamental do Programa: integrar três campos da educação que historicamente não estão muito próximos: o ensino médio, a formação profissional e a educação de jovens e adultos. Igualmente desafiante, na proposta, foi conseguir fazer com que as ofertas resultantes do Programa efetivamente contribuíssem para a melhoria das condições de participação social, política, cultural e no mundo

\footnotetext{
${ }^{3}$ http://www.incra.gov.br/educacao_pronera.

4 Para aprofundar a discussão sobre a gênese do Programa, sugerimos a leitura do artigo Proeja: entre desafios e possibilidades, de MOURA e HENRIQUE, disponibilizado na Revista HOLOS em <http://www2.ifrn.edu.br/ojs/index.php/HOLOS/article/view/914/536>.
} 
do trabalho dos jovens e adultos, em vez de produzir mais uma ação de contenção social. (MOURA; HENRIQUE, 2012).

Com a preocupação de elevar o nível de escolaridade dos estudantes, o Proeja visa oferecer oportunidades educacionais tanto a jovens e adultos que ainda não finalizaram o ensino fundamental $(E F)$, como àqueles que já o completaram, mas não concluíram o ensino médio (EM), nem um curso que os habilite em uma profissão. É importante frisar que os documentos da Secretaria de Educação Profissional e Tecnológica (SETEC) relativos a esse Programa trazem a preocupação de que haja a real integração do ensino médio com a educação profissional técnica em um único curso

fundamentando-se na concepção de educação unitária (ensino para a formação integral, geral e técnica, na perspectiva da superação da dualidade escolar) e de educação politécnica ou tecnológica, necessária à compreensão teórica e prática dos fundamentos científicos das múltiplas técnicas utilizadas no processo produtivo. (REGATTIERI; CASTRO, 2010, p. 36).

Assim, a formação profissional deve estar integrada à educação básica, formando uma totalidade, de forma a complementá-la e nunca substituí-la. Em outras palavras, deve organizarse na forma integrada, preferencialmente, embora a forma concomitante também esteja prevista legalmente,

Regattieri e Castro (2010), discutindo a Exposição de Motivos do Ministro da Educação ao Presidente da República, ao propor a edição do que veio a ser o Decreto no 5.154/2006, lembram que

O desenvolvimento da habilitação profissional no ensino médio é uma possibilidade legalmente respaldada e necessária aos jovens brasileiros, devendo-se assegurar a formação geral, consoante as finalidades dispostas no art. 35 e aos princípios curriculares a que se refere o art. 36 [da LDB]. (REGATTIERI; CASTRO, 2010, p. 34, grifo nosso).

Os princípios curriculares expressos no artigo 36 a que se refere o excerto acima foram substituídos pela determinação de organização curricular do EM composto pela Base Nacional Comum Curricular e por itinerários formativos.

Retomo, então, aqui as finalidades dispostas no Artigo 35 da atual LDB, não modificado pela Lei № 13.415/2017:

Art. 35. O ensino médio, etapa final da educação básica, com duração mínima de três anos, terá como finalidades:

I - a consolidação e o aprofundamento dos conhecimentos adquiridos no ensino fundamental, possibilitando o prosseguimento de estudos;

II - a preparação básica para o trabalho e a cidadania do educando, para continuar aprendendo, de modo a ser capaz de se adaptar com flexibilidade a novas condições de ocupação ou aperfeiçoamento posteriores;

III - o aprimoramento do educando como pessoa humana, incluindo a formação ética e o desenvolvimento da autonomia intelectual e do pensamento crítico; 
IV - a compreensão dos fundamentos científico-tecnológicos dos processos produtivos, relacionando a teoria com a prática, no ensino de cada disciplina. (BRASIL, 1996, s.p.)

Como o Proeja também está atrelado ao Artigo 36, o transcrevemos, a seguir, da atual LDB com as alterações impostas pela Lei 13.415/2017.

O currículo do ensino médio será composto pela Base Nacional Comum Curricular e por itinerários formativos, que deverão ser organizados por meio da oferta de diferentes arranjos curriculares, conforme a relevância para o contexto local e a possibilidade dos sistemas de ensino, a saber:

I - linguagens e suas tecnologias;

II - matemática e suas tecnologias;

III - ciências da natureza e suas tecnologias;

IV - ciências humanas e sociais aplicadas;

V - formação técnica e profissional.

$\S 1$ ㅇ A organização das áreas de que trata o caput e das respectivas competências e habilidades será feita de acordo com critérios estabelecidos em cada sistema de ensino. (BRASIL, 1996, n.p.).

Segundo o exposto, pela legislação, o Proeja EM está vinculado tanto às finalidades do EM como à Base Nacional Comum Curricular e aos itinerários formativos expressos na nova redação do Artigo 36 supracitado.

Considerando que estamos discutindo o EMI Proeja, devemos lembrar também que o artigo 36-A, da Seção IV-A, que trata da Educação Profissional Técnica de Nível Médio, explicita que "[...] o ensino médio, atendida a formação geral do educando, poderá prepará-lo para o exercício de profissões técnicas." (BRASIL, 1996, s.p., grifo nosso). Além disso, está assegurado pela legislação que os diplomas de cursos de EPTNM habilitarão ao prosseguimento de estudos na educação superior e na educação profissional tecnológica.

Analisando a legislação vigente e a fim de atender ao estabelecido para o EM e para a EPTNM na perspectiva do Proeja, pode-se concluir que se deve manter a garantia de uma carga horária mínima para a educação geral que propicie o cumprimento dos objetivos dessa etapa final da educação básica, que tem como finalidades a preparação para o trabalho e a cidadania do educando, seu aprimoramento como pessoa humana, incluindo a formação e os conhecimentos que possibilitem o prosseguimento de estudos, tanto na educação superior quanto na educação profissional e tecnológica sem desconsiderar a possibilidade de inserção no mundo do trabalho e na sociedade em constante mutação.

Então, caso não haja mudança na legislação, as alterações do EM propostas pela Lei № 13.415/2017 vão afetar não só o EMI como o Proeja. Cumpre lembrar que essa Lei não faz qualquer referência à modalidade EJA. 
Nessas circunstâncias, não se pode esquecer os pressupostos e princípios que orientam as ações desse Programa e tampouco podemos esquecer as especificidades do público-alvo do Proeja com suas singularidades (jovens, adultos, trabalhadores, população do campo, mulheres, negros, pobres) e a quem foi negado o direito de acesso ou de conclusão da EB na faixa etária dita própria ou regular.

No tocante aos pressupostos, o primeiro deles é a compreensão de que os humanos somos seres histórico-sociais e o segundo enfatiza que a realidade concreta é uma totalidade, síntese de múltiplas relações. Partindo desses pressupostos falar de formação humana integral implica integrar, no processo educativo, as dimensões do trabalho, da ciência, da cultura e da tecnologia, visando à formação omnilateral do sujeito.

Concordamos com Moura (2016, p.383), quando o autor afirma que

É importante destacar que, para o sujeito adulto, essa integração a partir do trabalho como princípio educativo em suas dimensões ontológica e histórica é muito significativa, pois uma característica fundamental dos adultos é a responsabilidade pela produção material da própria existência, o que se faz por meio do trabalho, o qual, no capitalismo, se dá sob a forma do emprego para a classe trabalhadora.

Essa preocupação com a formação para o trabalho, é importante, mas a finalidade da educação no Proeja não pode se resumir a ela. Cumpre lembrar que não se trata de preparar para a assunção de um posto de trabalho na sociedade, mas de proporcionar a formação integral de jovens e adultos atendidos por meio de cursos que integrem trabalho, ciência, tecnologia e cultura como eixos estruturantes do currículo.

Entretanto, lembra Moura (2016, p. 383) que a função da educação como preparação para o mercado

[...] é amplamente difundida pela ideologia do capital como sendo, praticamente, o único papel da escola e cuja síntese é: cabe à educação escolar formar para o mercado de trabalho e é responsabilidade dos sujeitos buscar a formação que lhes "garanta" a empregabilidade. Essa percepção do papel da educação escolar é naturalizada pela sociedade do capital, inclusive, por grande parte da classe trabalhadora e pelo sistema educacional, reduzindo a formação humana à aquisição de competências para a empregabilidade e para o empreendedorismo, o que vem se agudizando sob a égide neoliberal.

É essa concepção estreita de educação que está subjacente à Lei № 13.415/2017 que reforma o EM. Saviani (2016), no texto Educação Escolar, Currículo e Sociedade: O Problema da Base Nacional Comum Curricular, mostra que, ao se deslocar a determinação do currículo dos saberes construídos socialmente e colocar como cerne dessa definição os objetivos educacionais, então, são os objetivos que determinarão os conteúdos que comporão o currículo. 
Nessa linha de raciocínio, podemos fazer a seguinte dedução: parte-se daquilo que o mercado de trabalho necessita em termos de mão de obra, para se definirem competências e habilidades (ou "direitos e objetivos de aprendizagem", conforme expresso na Lei № 13.415/2017 e nas BNCC) para se decidir, então, que conteúdos deverão ser objeto do trabalho pedagógico na escola, qual o tempo dessa formação e até, como no caso da nova lei, determinar que ao estudante lhe está permitido apenas mais um itinerário formativo, caso haja vagas na Rede, conforme se pode ver no parágrafo quinto do artigo 36. "Os sistemas de ensino, mediante disponibilidade de vagas na rede, possibilitarão ao aluno concluinte do ensino médio cursar mais um itinerário formativo de que trata o caput." (BRASIL, 2017a, n.p., grifo nosso)

A escolha de "direitos e objetivos de aprendizagem" feita pelos responsáveis pela construção das BNCC, não visa a transmissão dos conhecimentos historicamente sistematizados e referenciados na prática social humana, como propõe o currículo na perspectiva da pedagogia histórico-crítica. Na visão de Marsiglia, Pina, Machado e Lima (2017),

Ao enfatizar as habilidades, as competências, os procedimentos e a formação de atitudes, e ao não destacar os conteúdos escolares, o trabalho educativo e o ensinar, o documento traz uma perspectiva que visa adaptar os alunos ao mercado de trabalho ou, mais propriamente, ao empreendedorismo. (MARSIGLIA; PINA; MACHADO; LIMA, 2017, p. 119).

Em outras palavras, o objetivo é preparar os filhos da classe trabalhadora para um mercado do trabalho precarizado, compatível com as novas demandas do capital para este século (MARSIGLIA; PINA; MACHADO; LIMA, 2017). Essa concepção de currículo está acorde com as reformas trabalhistas propostas pelo atual governo. Prepara a mão de obra que irá trabalhar submetida à legislação que ampara fortemente a classe empresarial em detrimento da classe trabalhadora.

Entre as justificativas expressas pelo governo para a reforma do ensino médio com a emissão Lei № 13.415/2017 estão o fortalecimento do EM, a flexibilização da trajetória escolar, para tornar a escola mais atrativa para o aluno, e a formação para o trabalho. A flexibilização vai se materializar em engessamento e fragmentação para o aluno. As ações do governo federal em relação à educação trazem uma coerência entre si, se complementam, estão estruturadas a partir de um currículo tecnicista e mostram uma concepção de uma educação instrumental, reduzida e barata, com forte talante tecnicista em detrimento dos aspectos que possam contribuir para uma formação humana, uma educação em que os conhecimentos historicamente sistematizados estão sendo negados aos sujeitos em formação. Dessa forma, explicitam, em seus novos documentos legais, a dualidade histórica que marca a educação brasileira.

Outra obra do governo atual nessa mesma direção é a proposta do MédioTec presencial e na modalidade de Educação a Distância, mais uma ação no âmbito do Pronatec, que retoma o Decreto 2.208/1997 que obrigatoriamente separava o EM da EP e atingiu duramente a rede federal de educação profissional. Segundo o Documento de Referência de Execução Para Todas as Redes Ofertantes, constante do Edital SETEC № 1/2017, como anexo III, 
O MedioTec tem como proposta o fortalecimento das políticas de educação profissional mediante a convergência das ações de fomento e execução, de produção pedagógica e de assistência técnica, para a oferta da educação profissional técnica de nível médio articulada de forma concomitante com as redes de educação e com o setor produtivo. (BRASIL, 2017b, n.p., grifo nosso)

Está explícito no documento que as demandas de formação técnica foram mapeadas em cada uma das cinco regiões do país, para se proporcionar mais sinergia entre a demanda e os cursos ofertados, com dados sobre as oportunidades "reais" de inserção, por município, e as aptidões formativas necessárias para atendê-las. É o mercado de trabalho regulando a educação. É a subordinação da educação às necessidades do mercado de trabalho. É a naturalização da educação como responsável apenas pela aquisição de competências para a empregabilidade.

Se pensarmos que aos sujeitos da EJA e do Proeja, com sua trajetória de interrupções e retorno à escola, já lhes foi negado esse conhecimento historicamente construído, o governo federal está mais uma vez negando a esses sujeitos o direito à educação socialmente referenciada. A proposta de se materializar, no Proeja, as funções reparadora, equalizadora e qualificadora, por meio das quais o Estado tem o dever de assegurar o direito de todos à educação, reduzindo a desigualdade entre os que tiveram acesso e aqueles aos quais o acesso à escola foi interditado, parece dar alguns passos atrás.

O Ensino Médio, foco das mudanças propostas pela Lei № 13.415/2017, é parte integrante e integrada dos cursos do Proeja. Dessa forma, as alterações propostas para essa etapa do ensino médio (caso não haja outras mudanças na legislação), também devem ser aplicadas a esse Programa. A forma integrada do EM está agonizante com a instituição do MédioTec, a fragmentação está presente com a determinação dos itinerários formativos, e, em consequência, a perspectiva da formação humana integral está ameaçada.

Um ponto de saída que se coloca é a autonomia pedagógica da Rede Federal. Uma pergunta que não quer calar: se o financiamento da educação profissional técnica de nível médio na educação presencial estiver vinculado à adesão ao MédioTec, tal como já ocorreu na Educação a distância, se pode falar em autonomia? ${ }^{5}$

\footnotetext{
5 No momento da revisão deste artigo para publicação, começam as ações do governo federal no sentido de cooptar institutos federais para a adoção da reforma do EM. A SETEC/MEC convidou dez IFs para apresentarem propostas para adoção do EM nos moldes da Lei № 13.415/2017. Em oposição a esse movimento, servidores públicos que atuam em todas as instituições da Rede Federal de Educação Profissional Científica e Tecnológica, intelectuais brasileiros, Movimento Nacional em Defesa do Ensino Médio, Sinasefe Brasília, Sinasefe Litoral de SC, Sintef Goiás e Goiano, e Grupo These, redigiram, em 20 de fevereiro deste ano, um manifesto denominado Primeiro Manifesto de 2018 em defesa do Ensino Médio Integrado e da Rede Federal de EPCT. Nesse documento, o grupo questiona, entre outros pontos, por que o Conselho Nacional das Instituições da Rede Federal de Educação Profissional, Científica e Tecnológica (CONIF), órgão que reúne as 41 instituições que compõem a Rede e é a instância de discussão, proposição e promoção de políticas de desenvolvimento da formação profissional e tecnológica, pesquisa e inovação
} 


\section{PARA CONTINUAR O DEBATE...}

A exemplo das ações históricas da esfera federal para a EJA, também o Proeja, tem sofrido reveses que dificultam sua continuidade. Lembramos que sua gênese, conforme discutimos em outro trabalho (MOURA; HENRIQUE, 2012), foi marcada por alguns equívocos importantes, que redundaram na criação de um grupo de trabalho plural que elaborou o Documento-Base de concepões e princípios do Programa. Como consequência, houve a substituição do Decreto inicial, № 5.478/2005 pelo Decreto № 5.840/2006; houve o financiamento de especialização voltada à formação de profissionais do ensino público para atuar no Proeja; as ações decorrentes do Edital Proeja-CAPES/SETEC № 03/2006, destinado a estimular a realização de projetos conjuntos de pesquisa entre as universidades e os IFs, que se materializam em produção de conhecimento no novo campo instituído. Houve também a realização dos encontros denominados Diálogos Proeja, ação voltada à formação de docentes, e ainda a produção de materiais destinados à formação docente, atendendo às especificidades dos níveis de ensino e da modalidade a que se destinavam (Proeja Técnico/Ensino Médio, Proeja Formação Inicial e Continuada/Ensino Fundamental e Proeja Indígena/Educação Profissional Integrada à Educação Escolar Indígena).

Essas iniciativas deram sustentação ao Programa, entretanto, foram iniciativas pontuais que, em não se repetindo, levaram à quase interrupção das ofertas das especializações e da produção de conhecimento por meio das pesquisas. Isso revela que o incentivo inicial do MEC não foi suficiente para institucionalizar esses cursos de especialização na Rede Federal de Educação Profissional e Tecnológica.

Como a Lei № 13.415/2017 separa o Ensino Técnico do Ensino Médio (dissimulada nos itinerários formativos específicos - quatro propedêuticos e um profissional) ela atinge o $\mathrm{EMI}$ e $\mathrm{o}$ Proeja. Segundo Cunha (2017), é um retorno à antiga concepção do EM como preparação para o trabalho para uns e formação para o Ensino Superior para outros. Na prática, e na melhor das hipóteses, para os egressos da Formação Técnica e Profissional restarão os cursos tecnológicos, mais curtos e específicos; para os demais, cursos profissionais plenos e os bacharelados interdisciplinares.

\section{REFERÊNCIAS}

BRASIL. LEI № 9.394, de 20 de dezembro de 1996. Estabelece as diretrizes e bases da educação nacional. Disponível em: <http://www.planalto.gov.br/ccivil_03/LEIS/L9394.htm>. Acesso em: 17 jul.2017.

não foi o interlocutor dessa ação; por que tampouco foi "convidado" para essa interlocução o Fórum de Dirigentes de Ensino (FDE), responsável pelas ações sistêmicas na área de educação na Rede de EPCT. O documento lembra que não existe, na lei de Reforma do EM, nenhum dispositivo que obrigue os IFs a adotarem a educação profissional concomitante ao ensino médio, ponto fundamental da reforma quando trata do itinerário profissional. Acrescentamos que a lei de criação da Rede de EPCT confere autonomia pedagógica às instituições constituintes e que a Rede, no Seminário Nacional do Ensino Médio Integrado, em setembro de 2017, reafirmou sua posição de manter o projeto do EMI. Diante do exposto, não podemos deixar de perguntar se esse "convite" da SETEC e da SEB não seria uma forma de dividir para conseguir seus objetivos, que, muito bem lembra o Manifesto, retomam antigas medidas como a Reforma Capanema, de 1942, a reforma pela Lei no 5.692, de 1971, e o Decreto no 2.208, de 1997? 
BRASIL. MINISTÉRIO DA EDUCAÇÃO. Educação Profissional Técnica de Nivel Médio Integrada ao Ensino Médio. Documento Base. 2007. Disponível em:

<portal.mec.gov.br/setec/arquivos/pdf/documento_base.pdf $>$. Acesso em: 17 jul.2017.

BRASIL. LEI № 13.415, de 16 de fevereiro de 2017. Altera as Leis $\mathrm{n}^{\text {os }}$ 9.394, de 20 de dezembro de 1996, que estabelece as diretrizes e bases da educação nacional, e 11.494, de 20 de junho 2007, que regulamenta o Fundo de Manutenção e Desenvolvimento da Educação Básica e de Valorização dos Profissionais da Educação, a Consolidação das Leis do Trabalho - CLT, aprovada pelo Decreto-Lei $\mathrm{n}^{\circ}$ 5.452, de $1^{\circ}$ - de maio de 1943, e o Decreto-Lei $\mathrm{n}^{\circ} \mathbf{2} 236$, de 28 de fevereiro de 1967; revoga a Lei $n^{\circ}-11.161$, de 5 de agosto de 2005; e institui a Política de Fomento à Implementação de Escolas de Ensino Médio em Tempo Integral. Disponível em: <www.planalto.gov.br/ccivil_03/_ato2015-2018/2017/lei/L13415.htm>. Acesso em: 17 jul.2017.

BRASIL. EDITAL SETEC № 01, de 02 de março de 2017. Apresentação de propostas para a oferta de vagas gratuitas em cursos técnicos na forma concomitante, no âmbito do Pronatec/Mediotec. 2017b. Disponível em: < http://portal.mec.gov.br/setec-secretaria-deeducacao-profissional-e-tecnologica/editais>. Acesso em: 04 jul. 2017.

CUNHA Luiz Antônio. Ensino Médio: Atalho para o Passado. In Educ. Soc., Campinas, v. 38, no. 139, p.373-384, abr.-jun., 2017.

HADDAD, Sérgio; DEL PIERRO, Maria Clara. Escolarização de jovens e adultos. Revista Brasileira de Educação, 2000, mai-ago., № 14, p. 108-130.

MARSIGLIA. Ana Carolina Galvão; PINA. Leonardo Docena; MACHADO. Vinícius de Oliveira; LIMA. Marcelo. A Base Nacional Comum Curricular: um novo episódio de esvaziamento da escola no Brasil. Germinal: Marxismo e Educação em Debate, Salvador, v. 9, n. 1, p. 107-121, abr. 2017.

MOURA, Dante Henrique; HENRIQUE, Ana Lúcia Sarmento. PROEJA: ENTRE DESAFIOS E POSSIBILIDADES. HOLOS, [S.I.], v. 2, p. 114-129, maio 2012. ISSN 1807-1600. Disponível em: <http://www2.ifrn.edu.br/ojs/index.php/HOLOS/article/view/914/536>. Acesso em: 18 jul. 2017. doi:http://dx.doi.org/10.15628/holos.2012.914.

MOURA, Dante Henrique. Programa Nacional de Integração da Educação Profissional com a Educação Básica na Modalidade de Educação de Jovens e Adultos - Proeja: entre potencialidades e entraves diante de projetos societários em disputa. Atas. XIII Sociedade Portuguesa de Ciências da Educação, 2016, p. 380-391.

PAIVA. Jane. Educação de Jovens e Adultos: direito, concepções e sentidos. 2005. 148f. Tese (Doutorado em Educação) - Programa de Pós-Graduação em Educação. Universidade Federal Fluminense, 2005.

REGATTIERI, Marilza; CASTRO, Jane Margareth. Ensino Médio e Educação Profissional: desafios da integração. Brasília: UNESCO, 2010. 
SAVIANI. Dermeval. EDUCAÇÃO ESCOLAR, CURRÍCULO E SOCIEDADE: o problema da Base Nacional Comum Curricular. In Movimento-revista de educação. Disponível em:

http://www.revistamovimento.uff.br/index.php/revistamovimento/article/view/296>; Acesso em: 04 jul 2017. 